Review

\title{
Splicing HAC1/XBP1 mRNAs in Cytoplasm: The Non-Conventional mRNA Splicing Reaction in the Unfolded Protein Response
}

Yi Song ${ }^{1,+}$, Carlos Rivera ${ }^{2,+}$, Jiayu Mai ${ }^{3,+}$, Annie Sun ${ }^{4,+}$, Weihan $\mathrm{Li}^{5, *}$

1. Department of Surgery, State University of New York Downstate Health Sciences University, Brooklyn, New York, USA; E-Mail: Yi.Song@downstate.edu

2. Section of Medical Oncology, Department of Internal Medicine, Yale School of Medicine, New Haven, CT, USA; E-Mail: carlos.rivera@yale.edu

3. Department of Management Science and Engineering, Stanford University, Stanford, California, USA; E-Mail: galahadm@stanford.edu

4. Burlingame High School, Burlingame, CA, USA; E-Mail: sunannie2002@gmail.com

5. Department of Anatomy and Structural Biology, Albert Einstein College of Medicine, Bronx, New York, USA; E-Mail: Weihan.Li@einsteinmed.org

$\dagger$ These authors contributed equally to this work.

* Correspondence: Weihan Li; E-Mail: Weihan.Li@einsteinmed.org

Academic Editor: Michael R. Ladomery

Special Issue: Alternative Splicing: A Key Process in Development and Disease

OBM Genetics

2020, volume 4, issue 2

doi:10.21926/obm.genet.2002110
Received: March 23, 2020

Accepted: May 15, 2020

Published: May 22, 2020

\begin{abstract}
The majority of the secretory and transmembrane proteins are folded in the endoplasmic reticulum (ER). When unfolded proteins accumulate in the ER, a collective of signalling pathways, termed the unfolded protein response (UPR), are activated to restore the ER protein folding homeostasis. The most evolutionarily conserved branch of UPR is mediated by the kinase/endoribonuclease Ire1. Ire1 mediates a cytosolic non-conventional mRNA splicing reaction of HAC1 mRNA in yeast and XBP1 mRNA in mammalian cells. The spliced $H A C 1 / X B P 1$ mRNA is translated and produces a functional transcription factor, which
\end{abstract}

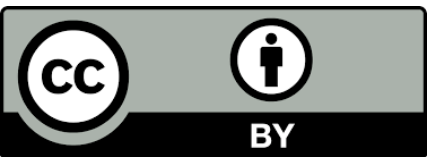

(C) 2020 by the author. This is an open access article distributed under the conditions of the Creative Commons by Attribution License, which permits unrestricted use, distribution, and reproduction in any medium or format, provided the original work is correctly cited. 
initiates a transcriptional response to restore the protein folding homeostasis. The $H A C 1 / X B P 1$ mRNA splicing reaction is biochemically distinct from the ones that are catalyzed by the spliceosome. Here, we review recent studies that provide a mechanistic understanding of the non-conventional mRNA splicing reaction.

\section{Keywords}

RNA biology; unfolded protein response; non-conventional mRNA splicing

\section{Introduction}

In eukaryotes, both transfer RNAs (tRNAs) and messenger RNAs (mRNAs) are subject to splicing. But the tRNA and mRNA splicing are biochemically distinct processes that utilize different molecular machineries. Precursor tRNAs are cleaved at two splice sites by the tRNA endoribonuclease, which are located mostly in nucleus for metazoans and in cytosol for Saccharomyces cerevisiae [1]. As a consequence, the precursor tRNAs are spitted into three pieces-the $5^{\prime}$-half tRNA, the intron and the 3'-half tRNA. Then, tRNA ligase joins the 5'- and 3'half tRNA, forming the spliced tRNA $[2,3]$. In comparison, the mRNA splicing is catalyzed in the nucleus by the spliceosome, which is composed of small nuclear RNAs and about 80 proteins [4]. Unlike the tRNA splicing reaction, the mRNA splicing reaction produces a lariat intermediate instead of cleavage fragments [4-6]. While tRNA and mRNA splicing are two independent processes, one mRNA-HAC1 mRNA in S. cerevisiae and XBP1 mRNA in metazoan-undergoes a non-conventional mRNA splicing reaction, which biochemically resembles the tRNA splicing reaction. The non-conventional mRNA splicing reaction was independently discovered by Peter Walter's and Kazutoshi Mori's lab in the 1990s when they discovered the unfolded protein response (UPR), which is a signaling pathway that maintains the protein folding homeostasis in the endoplasmic reticulum (ER) (Figure 1A) [7-12]. Under normal condition, the HAC1 mRNA contains a 252-nt intron. The intron forms a long-range basepairing with the HAC1 mRNA 5' UTR and creates a translational block. As a result, the un-spliced HAC1 mRNA is not translated [13-15]. When unfolded proteins accumulate in the ER, a condition termed ER stress, the HAC1 mRNA is cleaved by an endoribonuclease, Ire1, resulting in three intermediate fragments - the $5^{\prime}$ exon, the intron and the $3^{\prime}$ exon [16]. Then, the two exons undergo a conformational change, which positions the ends of the exons in close proximity $[17,18]$. Then, the tRNA ligase joins the $5^{\prime}$ and $3^{\prime}$ exons and completes the splicing reaction [19]. The spliced HAC1 mRNA produces the transcription factor Hac1, which transcriptionally increases the ER chaperone and the ER volume $[7,8,20]$. The ER-associated degradation is upregulated to degrade the unfolded proteins [21-23]. As a result, the ER's protein folding capacity increases and the proteins folding homeostasis is restored. The non-conventional mRNA splicing reaction is an evolutionarily conserved process of the UPR [24]. Mis-regulation of UPR leads to pathological effects. For example, prolonged UPR activation in pancreatic $\beta$-cells, in which large amount of insulin is produced, leads to apoptosis and type II diabetes [25]. Another example is that enveloped virus infections hijack the UPR pathways to increase ER folding capacity and assist in viral replication [26, 27]. Readers may refer to these articles [28-34] for a more comprehensive review on the physiological role of the UPR in 
health and disease. In this article, we summarize recent studies that focus on understanding the molecular mechanism of the HAC1/XBP1 mRNA splicing reaction.

\section{The Cleavage of the HAC1/XBP1 mRNA is Mediated by the Kinase/Endoribonuclease Ire1}

Ire1 is a single-pass transmembrane protein on the ER. Ire1 has an ER lumenal domain and a cytosolic kinase/endoribonuclease (RNase) domain. S. cerevisiae has one Ire1 homolog while mammalian cells have two Ire1 paralogs: Ire1 $\alpha$, expressed ubiquitously throughout the body, and Ire1 $\beta$, expressed only in the epithelial cells of airways and intestines [35-38]. Both mammalian Ire $1 \alpha$ and Ire1 $\beta$ catalyze the XBP1 mRNA splicing, but with different efficiency $[9,39,40]$. Upon ER stress, Ire1's lumenal domain senses the unfolded proteins and triggers Ire1 to oligomerize [41-56]. The oligomerized Ire1 undergoes trans-autophosphorylation, which activates the RNase domain $[53,57-60]$. A recent study discovered that the RNase activation is mediated by an interdomain helix between the Ire1's kinase and RNase domains [61]. The activated RNase domain cleaves the $H A C 1 / X B P 1$ mRNA at the two splice sites, separating the two exon fragments from the intron fragment $[16,62]$. The Ire1-mediated cleavage is the first step of the non-conventional mRNA splicing.

The substrate specificity of Ire1's RNase domain ensures that the cleavages only occur at the two splice sites on the HAC1/XBP1 mRNAs. S. cerevisiae Ire1 recognizes CNG|CNGN or CNG|ANGN ("I" represents the cleavage site) on a stem loop, of which the loop size is $7[18,62,63]$. Mammalian Ire1 $\alpha$ recognizes CNG $\mid$ CNGN on a stem loop, of which the loop size ranges from 5 to 9 $[18,64-66]$. Recent findings showed that the Ire1's RNase specificity is regulated by its phosphorylation and oligomeric state [57, 67-69]. In a study by Tam and colleagues [69], they found that the yeast Ire1 has a stringent RNase activity when forming high-order oligomers but has a promiscuous RNase activity when forming low-order oligomers (like dimers). In contrast, in a study by Han and colleagues [68], they found that the mammalian Ire $1 \alpha$ has a promiscuous RNase activity when forming high-order oligomers but has a stringent RNase activity when forming loworder oligomers. Further studies are needed to reconcile the two observations and gain a structural understanding on the Ire1's RNase specificity.

\section{An RNA Conformational Change Prepares the HAC1/XBP1 mRNA Exons for Ligation}

Post Ire1-mediated cleavages, three intermediate fragments are produced: the $5^{\prime}$ exon, the intron and the $3^{\prime}$ exon. A recent study reported that an RNA conformational change positions the ends of the exons in close proximity to prepare them for the subsequent ligation reaction [17]. Specifically, the flanking sequence of the two splice sites on HAC1/XBP1 mRNA is predicted to form a secondary structure, which resembles the letter " $Y$ " (Figure 1A). The $Y$-shaped RNA structure has three stems: the central stem (S1) and the two arm stems (S2 and S3). The two spliced sites are located on the stem-loops of S2 and S3. Post Ire1-mediated cleavages, the S2 and S3 stems are replaced by an extended S1 stem. As a result, this conformational change ejects the intron and physically tethers the two exons together. The ends of the two exons are positioned in close proximity, ready for the ligation reaction. If the Y-shaped structure is disrupted, the mutant mRNA cannot be efficiently ligated [17].

The importance of the Y-shaped RNA structure is further highlighted in our recent study, in which we reconstituted the non-conventional mRNA splicing reaction in vivo [18]. Our study was 
performed in Schizosaccharomyces pombe, where the HAC1/XBP1 homolog is absent [70, 71]. Instead of catalyzing the non-conventional mRNA splicing, the $S$. pombe Ire1 selectively cleaves and degrades a set of mRNAs at the ER periphery. This process, known as the regulated Ire1dependent mRNA decay (RIDD), reduces influx of ER protein folding burden and restores ER homeostasis [72]. RIDD was first discovered in Drosophila melanogaster and later found to be evolutionarily conserved [39, 66, 72-79]. RIDD is important for tissues undergoing intense secretory function, like the pancreatic $\beta$-cells $[68,80]$. RIDD mRNA substrates contain the consensus sequence and structure motif that can be recognized by Ire $1[18,65,66]$. These mRNAs are cleaved in the vicinity of ER translocons, where the mRNAs are translated [72, 81, 82]. Unlike HAC1/XBP1 mRNAs, RIDD mRNAs lack the Y-shaped structure to coordinate cleavage fragments. As a consequence, the fragments are physically separated post cleavage and degraded by housekeeping machineries, rather than being ligated by tRNA ligase (Figure 1B). To show the essential role of the Y-shaped RNA structure, we modified an S. pombe mRNA by replacing the Ire1 cleavage site with a Y-shaped RNA cassette, the modified mRNA was non-conventionally spliced by Ire1 in an ER-stress dependent manner. Thus, the Y-shaped RNA structure is the key element that separates a splicing substrate from a RIDD substrate (Figure $1 A, B)[18,83]$. Together, these results showed that the RNA conformational change is a critical step of the splicing reaction.

\section{The Ligation of the HAC1/XBP1 mRNA Exons is Mediated by the tRNA Ligase}

Sidrauski and colleagues first discovered that the yeast tRNA ligase Trl1 joins the two HAC1 mRNA exons. They found that a Trl1 mutant, which harbors a point mutation $\mathrm{H} 148 \mathrm{Y}$, cannot mediate the HAC1 mRNA splicing but can still mediate the tRNA splicing [19]. The mechanism of this functional separation was recently uncovered based on the crystal structure of Trl1 [84]. Trl1 $\mathrm{H} 148 \mathrm{Y}$ was found to be located near the catalytic site and compromises the ligation kinetics of Trl1. As a result, the HAC1 mRNA 5' and 3' exons cannot be efficiently ligated and are degraded by the Ski exosome complex and Xrn1. Thus, the HAC1 mRNA splicing is a well-balanced kinetic competition between mRNA decay and ligation [84, 85].

In metazoans, the identity of the ligase had been elusive because Trl1 is not evolutionarily conserved [86]. In 2014, four labs independently reported that RTCB, which is the catalytic subunit of the metazoan tRNA ligase complex, and its co-factor archease ligate the XBP1 mRNA exons [8790]. When RTCB or archease is conditionally knocked out, the XBP1 mRNA 5' and $3^{\prime}$ exons cannot be ligated [87-90]. In professional secretory cells, like the plasma cells, depleting RTCB decreases its ER protein folding capacity and, subsequently, its antibody production [87]. When simultaneously expressed in S. cerevisiae cells, mammalian RTCB and archease can catalyze the ligation reaction of yeast HAC1 mRNA exons [91]. Interestingly, a recent study showed that a tyrosine phosphorylation on RTCB reduces the enzyme's efficiency to ligate XBP1 mRNA exons, suggesting additional layers of regulation [92]. Together, these studies showed that the tRNA ligase catalyzes the ligation step of the non-conventional mRNA splicing reaction in both fungi and metazoans.

\section{Concluding Remarks}

The non-conventional mRNA splicing reaction is a uniquely evolved process in the UPR. Much mechanistic insight has been gained in the past two decades. The process employs three essential 
elements, including two trans-acting proteins-Ire1 and tRNA ligase-and one cis-acting element-the $\mathrm{Y}$-shaped RNA structure (Figure 1A). In contrast, RIDD substrates lack the Y-shaped RNA structure and are degraded post Ire1 cleavage (Figure 1B) [18]. Even though both XBP1 mRNA splicing and RIDD alleviate ER stress, they have different physiological functions in mammalian cells. It was suggested that XBP1 mRNA splicing is cyto-protective while RIDD is involved in apoptosis [68, 93-96]. A key question is to understand how the XBP1 mRNA splicing and RIDD are distinctively regulated. The heart of this question lies at the RNase specificity of Ire1. If Ire1's RNase activity becomes promiscuous, the substrate scope of RIDD increases and RIDD dominates. On the other hand, if Ire1's RNase activity becomes stringent, the substrate scope of RIDD decreases and XBP1 pathway dominates. Thus, future studies are needed to gain a structural understanding of Ire1's RNase specificity.

A

HAC1/XBP1 mRNA

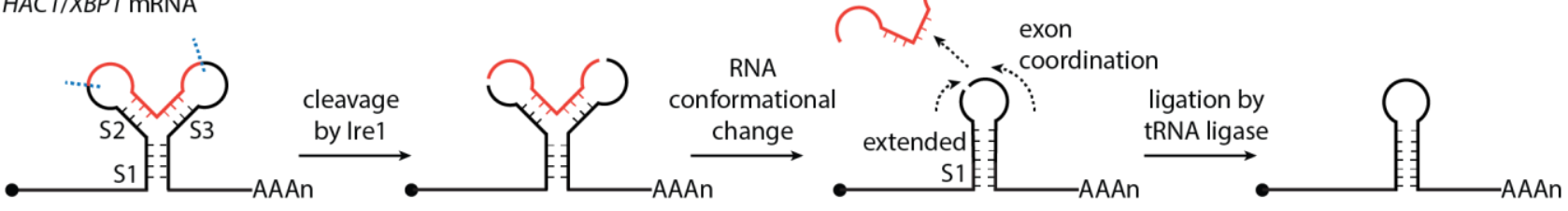

B

RIDD substrate mRNA

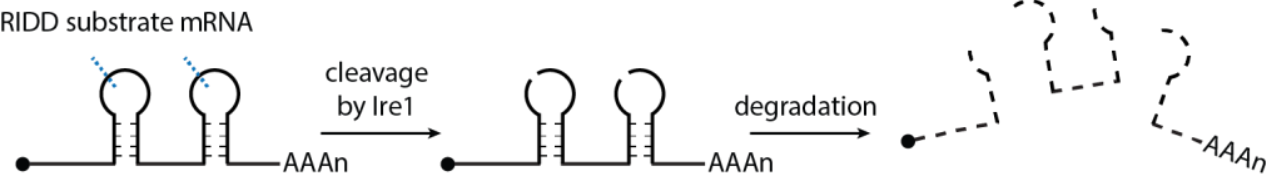

Figure 1 The model of the non-conventional mRNA splicing and RIDD. (A) The model of the HAC1/XBP1 mRNA splicing. The red RNA segment represents the intron. Blue dashed lines mark the two Ire1 cleavage sites. Dashed arrow lines indicate the movements of the corresponding intron or exon. The RNA stems S1, S2 and S3 constitute the Y-shaped mRNA structure. (B) The model of the RIDD process. Blue dashed lines mark the Ire1 cleavage sites.

\section{Author Contributions}

Supervision: W.L.

Conceptualization: W.L.

Manuscript drafting and editing: Y.S., C.R., J.M., A.S. and W.L.

\section{Funding}

This work is supported by High School Intern Program at University of California San Francisco (J.M.) and Howard Hughes Medical institute's Exceptional Research Opportunities Program (C.R.).

\section{Competing Interests}

The authors have declared that no competing interests exist. 


\section{References}

1. Chatterjee K, Nostramo RT, Wan Y, Hopper AK. tRNA dynamics between the nucleus, cytoplasm and mitochondrial surface: Location, location, location. Biochim Biophys Acta Gene Regul Mech. 2018; 1861: 373-386.

2. Abelson J, Trotta CR, Li H. tRNA splicing. J Biol Chem. 1998; 273: 12685-12688.

3. Greer $\mathrm{CL}$, Peeblesab CL, Gegenheimer $\mathrm{P}$, Abelson J. Mechanism of action of a yeast RNA ligase in tRNA splicing. Cell. 1983; 32: 537-546.

4. Shi Y. Mechanistic insights into precursor messenger RNA splicing by the spliceosome. Nat Rev Mol Cell Biol. 2017; 18: 655-670.

5. Berget SM, Moore C, Sharp PA. Spliced segments at the $5^{\prime}$ terminus of adenovirus 2 late mRNA. Proc Natl Acad Sci USA. 1977; 74: 3171-3175.

6. Chow LT, Gelinas RE, Broker TR, Roberts RJ. An amazing sequence arrangement at the 5 ' ends of adenovirus 2 messenger RNA. Cell. 1977; 12: 1-8.

7. Cox JS, Shamu CE, Walter P. Transcriptional induction of genes encoding endoplasmic reticulum resident proteins requires a transmembrane protein kinase. Cell. 1993; 73: 11971206.

8. Mori K, Ma W, Gething MJ, Sambrook J. A transmembrane protein with a cdc2+/CDC28related kinase activity is required for signaling from the ER to the nucleus. Cell. 1993; 74: 743756.

9. Calfon M, Zeng $\mathrm{H}$, Urano F, Till JH, Hubbard SR, Harding HP, et al. IRE1 couples endoplasmic reticulum load to secretory capacity by processing the XBP-1 mRNA. Nature. 2002; 415: 92-96.

10. Ron D, Walter P. Signal integration in the endoplasmic reticulum unfolded protein response. Nat Rev Mol Cell Biol. 2007; 8: 519-529.

11. Walter $P$, Ron $D$. The unfolded protein response: From stress pathway to homeostatic regulation. Science. 2011; 334: 1081-1086.

12. Karagoz GE, Aragon T, Acosta-Alvear D. Recent advances in signal integration mechanisms in the unfolded protein response. F1000Res. 2019; 8.

13. Ruegsegger $\mathrm{U}$, Leber $\mathrm{JH}$, Walter $\mathrm{P}$. Block of HAC1 mRNA translation by long-range base pairing is released by cytoplasmic splicing upon induction of the unfolded protein response. Cell. 2001; 107: 103-114.

14. Sathe $\mathrm{L}$, Bolinger $\mathrm{Cl}$, Mannan MA, Dever TE, Dey M. Evidence that base-pairing interaction between intron and mRNA leader sequences inhibits initiation of HAC1 mRNA translation in yeast. J Biol Chem. 2015; 290: 21821-21832.

15. Xia X. Translation control of HAC1 by regulation of splicing in saccharomyces cerevisiae. Int J Mol Sci. 2019; 20: 2860.

16. Sidrauski $C$, Walter $P$. The transmembrane kinase Ire1p is a site-specific endonuclease that initiates mRNA splicing in the unfolded protein response. Cell. 1997; 90: 1031-1039.

17. Peschek J, Acosta-Alvear D, Mendez AS, Walter P. A conformational RNA zipper promotes intron ejection during non-conventional XBP1 mRNA splicing. EMBO Rep. 2015; 16: 16881698.

18. Li W, Okreglak V, Peschek J, Kimmig P, Zubradt M, Weissman JS, et al. Engineering ER-stress dependent non-conventional mRNA splicing. Elife. 2018; 7: e35388. 
19. Sidrauski C, Cox JS, Walter P. tRNA ligase is required for regulated mRNA splicing in the unfolded protein response. Cell. 1996; 87: 405-413.

20. Schuck S, Prinz WA, Thorn KS, Voss C, Walter P. Membrane expansion alleviates endoplasmic reticulum stress independently of the unfolded protein response. J Cell Biol. 2009; 187: 525536.

21. Travers KJ, Patil CK, Wodicka L, Lockhart DJ, Weissman JS, Walter P. Functional and genomic analyses reveal an essential coordination between the unfolded protein response and ERassociated degradation. Cell. 2000; 101: 249-258.

22. Van Dalfsen KM, Hodapp S, Keskin A, Otto GM, Berdan CA, Higdon A, et al. Global proteome remodeling during ER stress involves HAC1-Driven expression of long undecoded transcript isoforms. Dev Cell. 2018; 46: 219-235.e8.

23. Brodsky JL, Skach WR. Protein folding and quality control in the endoplasmic reticulum: Recent lessons from yeast and mammalian cell systems. Curr Opin Cell Biol. 2011; 23: 464475.

24. Hollien J. Evolution of the unfolded protein response. Biochim Biophys Acta. 2013; 1833: 2458-2463.

25. Fonseca SG, Gromada J, Urano F. Endoplasmic reticulum stress and pancreatic beta-cell death. Trends Endocrinol Metab. 2011; 22: 266-274.

26. Li B, Gao B, Ye L, Han X, Wang W, Kong L, et al. Hepatitis B virus X protein ( $\mathrm{HBX}$ ) activates ATF6 and IRE1-XBP1 pathways of unfolded protein response. Virus Res. 2007; 124: 44-49.

27. Lazar C, Uta M, Branza-Nichita N. Modulation of the unfolded protein response by the human hepatitis B virus. Front Microbiol. 2014; 5: 433.

28. Lindholm D, Korhonen L, Eriksson O, Kõks S. Recent insights into the role of unfolded protein response in ER stress in health and disease. Front Cell Dev Biol. 2017; 5: 48.

29. Doultsinos D, Avril T, Lhomond S, Dejeans N, Guédat P, Chevet E. Control of the unfolded protein response in health and disease. SLAS Discov. 2017; 22: 787-800.

30. Hetz C, Axten JM, Patterson JB. Pharmacological targeting of the unfolded protein response for disease intervention. Nat Chem Biol. 2019; 15: 764-775.

31. Cybulsky AV. Endoplasmic reticulum stress, the unfolded protein response and autophagy in kidney diseases. Nat Rev Nephrol. 2017; 13: 681-696.

32. Bohnert KR, McMillan JD, Kumar A. Emerging roles of ER stress and unfolded protein response pathways in skeletal muscle health and disease. J Cell Physiol. 2018; 233: 67-78.

33. Kroeger $\mathrm{H}$, Chiang WC, Felden J, Nguyen A, Lin JH. ER stress and unfolded protein response in ocular health and disease. FEBS J. 2019; 286: 399-412.

34. Hetz C, Saxena S. ER stress and the unfolded protein response in neurodegeneration. Nat Rev Neurol. 2017; 13: 477-491.

35. Tirasophon $\mathbf{W}$, Welihinda AA, Kaufman RJ. A stress response pathway from the endoplasmic reticulum to the nucleus requires a novel bifunctional protein kinase/endoribonuclease (Ire1p) in mammalian cells. Genes Dev. 1998; 12: 1812-1824.

36. Wang XZ, Harding HP, Zhang Y, Jolicoeur EM, Kuroda M, Ron D. Cloning of mammalian Ire1 reveals diversity in the ER stress responses. EMBO J. 1998; 17: 5708-5717.

37. Bertolotti A, Wang XZ, Novoa I, Jungreis $\mathrm{R}$, Schlessinger $\mathrm{K}$, Cho JH, et al. Increased sensitivity to dextran sodium sulfate colitis in IRE1beta-deficient mice. J Clin Invest. 2001; 107: 585-593. 
38. Tsuru A, Fujimoto N, Takahashi S, Saito M, Nakamura D, Iwano M, et al. Negative feedback by IRE1beta optimizes mucin production in goblet cells. Proc Natl Acad Sci USA. 2013; 110: 28642869.

39. Nakamura D, Tsuru A, Ikegami K, Imagawa Y, Fujimoto N, Kohno K. Mammalian ER stress sensor IRE1beta specifically down-regulates the synthesis of secretory pathway proteins. FEBS Lett. 2011; 585: 133-138.

40. Imagawa $Y$, Hosoda A, Sasaka S, Tsuru A, Kohno K. RNase domains determine the functional difference between IRE1alpha and IRE1beta. FEBS Lett. 2008; 582: 656-660.

41. Karagoz GE, Acosta-Alvear D, Walter P. The unfolded protein response: Detecting and responding to fluctuations in the protein-folding capacity of the endoplasmic reticulum. Cold Spring Harb Perspect Biol. 2019; 11: a033886.

42. Pincus D, Chevalier MW, Aragón T, van Anken E, Vidal SE, El-Samad H, et al. BiP binding to the ER-stress sensor Ire1 tunes the homeostatic behavior of the unfolded protein response. PLoS Biol. 2010; 8: e1000415.

43. Gardner BM, Walter P. Unfolded proteins are Ire1-activating ligands that directly induce the unfolded protein response. Science. 2011; 333: 1891-1894.

44. Carrara M, Prischi F, Nowak PR, Kopp MC, Ali MM. Noncanonical binding of BiP ATPase domain to Ire1 and Perk is dissociated by unfolded protein $\mathrm{CH} 1$ to initiate ER stress signaling. Elife. 2015; 4: e03522.

45. Amin-Wetzel N, Saunders RA, Kamphuis MJ, Rato C, Preissler S, Harding HP, et al., A J-protein co-chaperone recruits BiP to monomerize IRE1 and repress the unfolded protein response. Cell. 2017; 171: 1625-1637.e13.

46. Karagoz GE, Acosta-Alvear D, Nguyen HT, Lee CP, Chu F, Walter P. An unfolded proteininduced conformational switch activates mammalian IRE1. Elife. 2017; 6: e30700.

47. Amin-Wetzel N, Neidhardt L, Yan Y, Mayer MP, Ron D. Unstructured regions in IRE1alpha specify BiP-mediated destabilisation of the luminal domain dimer and repression of the UPR. Elife. 2019; 8: e50793.

48. Preissler S, Ron D. Early events in the endoplasmic reticulum unfolded protein response. Cold Spring Harb Perspect Biol. 2019; 11: a033894.

49. Kopp MC, Nowak PR, Larburu N, Adams CJ, Ali MM. In vitro FRET analysis of IRE1 and BiP association and dissociation upon endoplasmic reticulum stress. Elife. 2018; 7: e30257.

50. Okamura K, Kimata $Y$, Higashio H, Tsuru A, Kohno K. Dissociation of Kar2p/BiP from an ER sensory molecule, Ire1p, triggers the unfolded protein response in yeast. Biochem Biophys Res Commun. 2000; 279: 445-450.

51. Zhou J, Liu CY, Back SH, Clark RL, Peisach D, Xu Z, et al., The crystal structure of human IRE1 luminal domain reveals a conserved dimerization interface required for activation of the unfolded protein response. Proc Natl Acad Sci USA. 2006; 103: 14343-14348.

52. Credle JJ, Finer-Moore JS, Papa FR, Stroud RM, Walter P. On the mechanism of sensing unfolded protein in the endoplasmic reticulum. Proc Natl Acad Sci USA. 2005; 102: 1877318784.

53. Korennykh AV, Egea PF, Korostelev AA, Finer-Moore J, Zhang C, Shokat KM, et al. The unfolded protein response signals through high-order assembly of Ire1. Nature. 2009; 457: 687-693. 
54. Aragon $T$, van Anken $E$, Pincus $D$, Serafimova IM, Korennykh AV, Rubio $C A$, et al., Messenger RNA targeting to endoplasmic reticulum stress signalling sites. Nature. 2009; 457: 736-740.

55. Li H, Korennykh AV, Behrman SL, Walter P. Mammalian endoplasmic reticulum stress sensor IRE1 signals by dynamic clustering. Proc Natl Acad Sci USA. 2010; 107: 16113-16118.

56. Belyy V, Tran NH, Walter P. Quantitative microscopy reveals dynamics and fate of clustered IRE1alpha. Proc Natl Acad Sci USA. 2020; 117: 1533-1542.

57. Prischi F, Nowak PR, Carrara M, Ali MMU. Phosphoregulation of Ire1 RNase splicing activity. Nat Commun. 2014; 5: 3554.

58. Rubio C, Pincus D, Korennykh A, Schuck S, El-Samad H, Walter P. Homeostatic adaptation to endoplasmic reticulum stress depends on Ire1 kinase activity. J Cell Biol. 2011; 193: 171-184.

59. Ali MM, Bagratuni T, Davenport EL, Nowak PR, Silva-Santisteban MC, Hardcastle A, et al. Structure of the Ire1 autophosphorylation complex and implications for the unfolded protein response. EMBO J. 2011; 30: 894-905.

60. Lee KP, Dey M, Neculai D, Cao C, Dever TE, Sicheri F. Structure of the dual enzyme Ire1 reveals the basis for catalysis and regulation in nonconventional RNA splicing. Cell. 2008; 132: 89-100.

61. Ricci D, Tutton S, Marrocco I, Ying M, Blumenthal D, Eletto D, et al., The interdomain helix between the kinase and RNase domains of IRE1 $\alpha$ transmits the conformational change that underlies ER stress-induced activation. BioRxiv. 2020; doi: https://doi.org/10.1101/2020.01.14.902395.

62. Gonzalez TN, Sidrauski C, Dörfler S, Walter P. Mechanism of non-spliceosomal mRNA splicing in the unfolded protein response pathway. EMBO J. 1999; 18: 3119-3132.

63. Kawahara $\mathrm{T}$, Yanagi $\mathrm{H}$, Yura $\mathrm{T}$, Mori K. Unconventional splicing of HAC1/ERN4 mRNA required for the unfolded protein response. Sequence-specific and non-sequential cleavage of the splice sites. J Biol Chem. 1998; 273: 1802-1807.

64. Poothong J, Sopha P, Kaufman RJ, Tirasophon W. IRE1alpha nucleotide sequence cleavage specificity in the unfolded protein response. FEBS Lett. 2017; 591: 406-414.

65. Oikawa D, Tokuda M, Hosoda A, Iwawaki T. Identification of a consensus element recognized and cleaved by IRE1 alpha. Nucleic Acids Res. 2010; 38: 6265-6273.

66. Moore K, Hollien J. Ire1-mediated decay in mammalian cells relies on mRNA sequence, structure, and translational status. Mol Biol Cell. 2015; 26: 2873-2884.

67. Tang $\mathrm{CH}$, Chang S, Paton AW, Paton JC, Gabrilovich DI, Ploegh HL, et al., Phosphorylation of IRE1 at S729 regulates RIDD in B cells and antibody production after immunization. J Cell Biol. 2018; 217: 1739-1755.

68. Han D, Lerner AG, Walle LV, Upton JP, Xu W, Hagen A, et al. IRE1alpha kinase activation modes control alternate endoribonuclease outputs to determine divergent cell fates. Cell. 2009; 138: 562-575.

69. Tam $A B$, Koong $A C$, Niwa $M$. Ire1 has distinct catalytic mechanisms for $X B P 1 / H A C 1$ splicing and RIDD. Cell Rep. 2014; 9: 850-858.

70. Kimmig P, Diaz M, Zheng J, Williams CC, Lang A, Aragón T, et al., The unfolded protein response in fission yeast modulates stability of select mRNAs to maintain protein homeostasis. Elife. 2012; 1: e00048.

71. Guydosh NR, Kimmig P, Walter P, Green R. Regulated Ire1-dependent mRNA decay requires no-go mRNA degradation to maintain endoplasmic reticulum homeostasis in S. pombe. Elife. 2017; 6: e29216. 
72. Hollien J, Weissman JS. Decay of endoplasmic reticulum-localized mRNAs during the unfolded protein response. Science. 2006; 313: 104-107.

73. Hollien J, Lin JH, Li H, Stevens N, Walter P, Weissman JS. Regulated Ire1-dependent decay of messenger RNAs in mammalian cells. J Cell Biol. 2009; 186: 323-331.

74. Maurel M, Chevet E, Tavernier J, Gerlo S. Getting RIDD of RNA: IRE1 in cell fate regulation. Trends Biochem Sci. 2014; 39: 245-254.

75. Mishiba K, Nagashima Y, Suzuki E, Hayashi N, Ogata Y, Shimada Y, et al., Defects in IRE1 enhance cell death and fail to degrade mRNAs encoding secretory pathway proteins in the Arabidopsis unfolded protein response. Proc Natl Acad Sci USA. 2013; 110: 5713-5718.

76. Miyazaki T, Nakayama H, Nagayoshi Y, Kakeya H, Kohno S. Dissection of Ire1 functions reveals stress response mechanisms uniquely evolved in Candida glabrata. PLoS Pathog. 2013; 9: e1003160.

77. Glazier VE, Panepinto JC. The ER stress response and host temperature adaptation in the human fungal pathogen Cryptococcus neoformans. Virulence. 2014; 5: 351-356.

78. Miyazaki T, Kohno S. ER stress response mechanisms in the pathogenic yeast Candida glabrata and their roles in virulence. Virulence. 2014; 5: 365-370.

79. Iwawaki T, Hosoda A, Okuda T, Kamigori Y, Nomura-Furuwatari C, Kimata Y, et al., Translational control by the ER transmembrane kinase/ribonuclease IRE1 under ER stress. Nat Cell Biol. 2001; 3: 158-164.

80. Lipson KL, Ghosh R, Urano $F$. The role of IRE1alpha in the degradation of insulin mRNA in pancreatic beta-cells. PLoS One. 2008; 3: e1648.

81. Plumb R, Zhang ZR, Appathurai S, Mariappan M. A functional link between the cotranslational protein translocation pathway and the UPR. Elife. 2015; 4: e07426.

82. Acosta-Alvear D, Karagöz GE, Fröhlich F, Li H, Walther TC, Walter P. The unfolded protein response and endoplasmic reticulum protein targeting machineries converge on the stress sensor IRE1. Elife. 2018; 7: e43036.

83. Li W. Regulating ER protein homeostasis by differentially processing mRNAs. California: eScholarship; 2018.

84. Peschek J, Walter P. tRNA ligase structure reveals kinetic competition between nonconventional mRNA splicing and mRNA decay. Elife. 2019; 8: e44199.

85. Cherry PD, Peach SE, Hesselberth JR. Multiple decay events target HAC1 mRNA during splicing to regulate the unfolded protein response. Elife. 2019; 8: e42262.

86. Popow J, Schleiffer A, Martinez J. Diversity and roles of (t)RNA ligases. Cell Mol Life Sci. 2012; 69: 2657-2670.

87. Jurkin J, Henkel T, Nielsen AF, Minnich M, Popow J, Kaufmann T, et al. The mammalian tRNA ligase complex mediates splicing of XBP1 mRNA and controls antibody secretion in plasma cells. EMBO J. 2014; 33: 2922-2936.

88. Kosmaczewski SG, Edwards TJ, Han SM, Eckwahl MJ, Meyer BI, Peach S, et al. The RtcB RNA ligase is an essential component of the metazoan unfolded protein response. EMBO Rep. 2014; 15: 1278-1285.

89. Lu Y, Liang FX, Wang X. A synthetic biology approach identifies the mammalian UPR RNA ligase RtcB. Mol Cell. 2014; 55: 758-770. 
90. Ray A, Zhang S, Rentas C, Caldwell KA, Caldwell GA. RTCB-1 mediates neuroprotection via XBP-1 mRNA splicing in the unfolded protein response pathway. J Neurosci. 2014; 34: 1607616085.

91. Poothong J, Tirasophon W, Kaufman RJ. Functional analysis of the mammalian RNA ligase for IRE1 in the unfolded protein response. Biosci Rep. 2017; 37: BSR20160574.

92. Papaioannou A, Metais A, Maurel M, Negroni L, González-Quiroz M, Zare Golchesmeh E, et al. Stress-induced tyrosine phosphorylation of RtcB modulates IRE1 activity and signaling outputs. bioRxiv. 2020; doi: https://doi.org/10.1101/2020.03.02.972950.

93. Lin JH, Li H, Yasumura D, Cohen HR, Zhang C, Panning B, et al. IRE1 signaling affects cell fate during the unfolded protein response. Science. 2007; 318: 944-949.

94. Hetz C, Papa FR. The unfolded protein response and cell fate control. Mol Cell. 2018; 69: 169181.

95. Lu M, Lawrence DA, Marsters S, Acosta-Alvear D, Kimmig P, Mendez AS, et al., Opposing unfolded-protein-response signals converge on death receptor 5 to control apoptosis. Science. 2014; 345: 98-101.

96. Upton JP, Wang L, Han D, Wang ES, Huskey NE, Lim L, et al. IRE1alpha cleaves select microRNAs during ER stress to derepress translation of proapoptotic Caspase-2. Science. 2012; 338: 818-822.

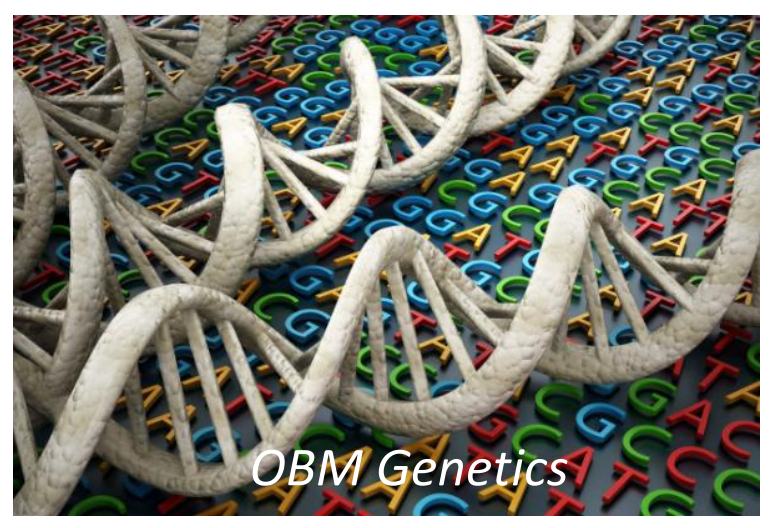

Enjoy OBM Genetics by:

1. Submitting a manuscript

2. Joining in volunteer reviewer bank

3. Joining Editorial Board

4. Guest editing a special issue

For more details, please visit: http://www.lidsen.com/journals/genetics 